
\title{
25 Research Square \\ Truncation Effect on Estimation of Transport Parameters for Slug-injection Tracer Tests
}

Tomoki Kurasawa ( $\nabla$ 178a052a@stu.kobe-u.ac.jp)

Kobe University: Kobe Daigaku https://orcid.org/0000-0003-4736-5245

\section{Yoshitaro Takahashi}

Kobe University: Kobe Daigaku

\section{Mariko Suzuki}

Kobe University: Kobe Daigaku

Kazuya Inoue

Kobe University: Kobe Daigaku

\section{Research Article}

Keywords: Slug-injection tracer test, Truncation , Analytical solution , Laboratory-scale experiment, Transport parameter, Spatial moment analysis

Posted Date: July 1st, 2021

DOI: https://doi.org/10.21203/rs.3.rs-560647/v1

License: (1) (1) This work is licensed under a Creative Commons Attribution 4.0 International License. Read Full License

Version of Record: A version of this preprint was published at Environmental Earth Sciences on March 1st, 2022. See the published version at https://doi.org/10.1007/s12665-022-10309-9. 


\section{Abstract}

For slug-injection tracer tests, tracer concentrations below the detection limit of the measurement instrument can cause truncation of the observed data. This study investigated the truncation effect on the estimation error of parameters based on analytical solutions and the results of a laboratory-scale experiment. Spatial moment analysis was performed to estimate the measured total mass and transport parameters, including the pore velocity and the longitudinal and transverse dispersivities. Increasing the travel distance and detection limit caused the measured mass and dispersivities to be underestimated regardless of the dimensionality because hydrodynamic dispersion occurs with increasing travel distance, which smoothens the concentration front. The one- and two-dimensional cases showed that the truncation effect on the measured mass and longitudinal dispersivity depended on dimensionality. In contrast, the pore velocity showed no such dependence; the center of mass did not change as the unmeasured portion due to truncation was increased because the plume, which exhibited a Gaussian distribution, was truncated symmetrically. In the experiment, the measured mass and dispersivities likewise depended on the travel distance and detection limit, but there were large differences in the detection limit at which the dimensionless parameter reached a value of zero between the experimental results and analytical solution. This is because the initial plume in the experiment was of a finite size. Thus, experimental design factors such as the scale, device, and dimensionality should be considered to minimize the estimation error of transport parameters, excluding the pore velocity.

\section{Full Text}

This preprint is available for download as a PDF. 